\title{
Participation in Decision Making: Disempowerment, Disappointment and Different Directions
}

Joy Trotter PhD, CQSW, Reader in Social Work, School of Health \& Social Care, University of Teesside, Middlesbrough, Cleveland

and

Carol Campbell PhD, BSc (Hons), CPsychol, Senior Lecturer in Psychology, School of Social Sciences and Law, University of Teesside, Middlesbrough, Cleveland

Joy Trotter is Reader in Social Work in the School of Health and Social Care at the University of Teesside, UK. Her research and publication interests include domestic violence and child sexual abuse, though her work focuses mostly on young people and sexuality issues. She is Chair of ATSWE (the Association of Teachers in Social Work Education) and founder of the National Symposium on Sexuality in Social Work Practice, Education and Research.

Carol Campbell is a Senior Lecturer in Psychology in the School of Social Sciences and Law at the University of Teesside, UK. Her research and publication interests include health psychological issues, particularly pain and stress but also ethical issues in research. 


\section{Participation in Decision Making: Disempowerment, Disappointment and Different Directions}

\section{Summary}

This paper considers the positioning within British social care research, of young disengaged people who are 'invisible' to formal support services. Using a recently completed research project as illustration and focussing primarily on mental health and wellbeing, it raises questions regarding the practical and ethical implications of engaging such young people to actively participate in research and other decision-making endeavours. We aimed to engage and empower young people ${ }^{1}$ (who were not in employment, education or training) by enlisting them as co-researchers, with youth-friendly technology (mobile phones, video cameras, and MSN messaging) and involve them in decisions relating to each stage as the research progressed. We adopted separate roles in the process: Carol provided consultation and project oversight, Joy worked as the primary researcher with the key support agency and the young researchers.

Throughout the research project we questioned the practical and ethical implications of 'involving' the young people as co-researchers. The fact that the young people were paid for each element of their involvement in the project, the use of 'inducements' and the 'training' of these young people to be co-researchers, felt exploitative rather than empowering. However, a small number of the young people continued with the project and, resisting the suggestions and aspirations of the researchers, made their own decisions and set their own agendas. In addition, one of the young men experienced a marked increase in social engagement and improved wellbeing.

Key words: participation, exclusion, young people, power, decision-making, ethics 
[4644 words (5861 with references)]

\section{Participation in Decision Making: Disempowerment, Disappointment and Different Directions}

\section{Introduction}

In the UK, as part of the 2007 Comprehensive Spending Review, the British Government is currently assessing progress made to improve outcomes and life chances of children and young people (HM Treasury \& Department for Education \& Skills, 2007) and intends to draw on the increasing body of research that has involved young people themselves. As user-involvement has continued to develop in health and social research fields in the UK, many more voices have been heard (Clough et al, 2006; Lowes \& Hulatt, 2005; Ross, et al, 2005; Thornton, 2002). Many of these have been about mental health issues (Trivedi \& Wykes, 2002; Carrick et al, 2001; Faulkner \& Thomas, 2002). These voices however, have usually been linked with an agency, institution or service, or 'belonged' to some kind of user-organisation (Leamy \& Clough, 2002; Jones et al, 2004). On the whole, they have not been disparate, invisible, hard-to-reach, mis-fits or outsiders. Unlike much of the research in health and social care arenas, which is focussed on already identified and categorised populations (for example school students, clinic patients or day-centre attendees), this research project attempted to focus on young people who 'fell outside' such populations.

This paper is based on this small research project which was undertaken in 2004 (commissioned by one key support agency) in the North East of England, an area which has a history of socioeconomic problems and a predominantly white population. The project involved three young researchers, aged between 17 and 21 years, who were not in employment, education or training (referred to as NEET) and were also 'outside' and 'not engaged' with any formal health projects or 
social programmes. Research with young people presents a number of challenges, especially when they are already disinclined to engage with formal organisations or official endeavours (Bennett et al, 2003). However, as qualified social work and health professionals with a broader set of clinical, practical and research experiences, the authors are in a position to work with and explore a more challenging range of issues and individuals.

\section{Background Literature}

Much of the research in social work and social care around young people and mental health and wellbeing, address issues of exclusion and marginalisation (Aggleton et al, 2000; Morrison \& L'Heureux, 2002; Department of Health, 2004) and recognises factors associated with low selfesteem and identity (Swann \& Spivey, 2004; Turner et al, 2006). A good deal of the literature also acknowledges the difficulties in providing appropriate services for young people and emphasises how time-consuming and emotionally challenging work in this area can be (Oliver \& Storey, 2006; Anderson, 2005; University of Sheffield, 2005) especially with disaffected or socially excluded groups (McLeod, 2008). Many young people are fearful and often angry in what they perceive as threatening environments, and a number of studies (Keen, 2004; Gilchrist \& Sullivan, 2006) argue that it is important to offer services that are relaxing, safe and non-confrontational. The literature about work around young people and suicide suggests that it is a complex and highly unpredictable area (Crowley et al, 2004; Stanley, 2005; Trickey, 2005; Smalley et al, 2005) and it appears that non-statutory and youth-oriented agencies might be better placed than formal organisations and services to do this work (National Institute for Mental Health in England, 2006).

The psychological literature addresses many similar themes. The positioning of young people at the margins of society leads to a propensity for poorer physical health and negative affect that is quantified by higher indices of depression; stress and anxiety (see Baker, 2003). According to the literature, salient psychosocial stressors that marginalised young people and their families 
struggle with, include relationship breakdowns, teenage pregnancy, family deaths, serious criminal behaviour, gambling, financial problems and often serious physical illness. Yet despite this catalogue of deleterious life events and episodes many older young people from these marginalised and excluded populations remain 'hard-to-engage' client groups (Fortune et al 2007, p.209). Furthermore, young men with histories of behavioural difficulties and poor attachment represent one of the most challenging groups to access in order to engage them with any form of health related intervention or strategy. Circuitously, such patterns of behaviour, detrimental to their well-being, should serve as a beacon to potential distress and trigger the support of welfare and social services. However, their historic low engagement with such services has undoubtedly compounded their 'invisibility'. One consequence of this (invisibility and exclusion) is an urgency to involve young people in relation to service provision (addressing space and place) and service development (meeting needs). One method identified that may be able to achieve this, is through involving young people from the outset in research about them and about the services provided for them.

Smith et al (2002) discuss key methodological issues arising from their large-scale study concerned with addressing the health needs of young people. They engaged young people as collaborative co-researchers across three sites in the North of England and describe the main challenges they overcame whilst involving young people in the research process. Overall, the project was successful and 'added value' (p. 204) through the consideration of the way that health care is experienced and perceived by the young people themselves. The young people also provided insight into the professional arrogance that they perceived from some individuals within the health services and clearly such a participatory research role enabled such data to emerge. By following the process adopted by Smith et al we aimed to engage young service users within a participatory research framework. Furthermore, by using Hanley et al's (2004) wide-ranging notion of collaboration (whereby the adult researcher shares ownership of the research acting 
both collegially and enabling co-researchers to be influential in the research process) we endeavoured to focus on the outcomes of such collaborative user involvement rather than the research process per se.

\section{Research Aims}

The aims of the research were threefold. Firstly, in order to fulfil the requirements of the commissioning agency, we aimed to

- provide a comprehensive understanding of the needs and achievements of young people categorised as NEET, and

- identify any areas for future support service development.

Secondly, the authors wished to avoid alienating young people from vital sources of knowledge and motivation by giving more recognition to the learning and experience that young people acquire in the non-institutionalised parts of their lives (Evans et al 2003). In order to achieve this, the research methodologies were chosen to

- actively engage and empower the young people within the research project rather than view them as passive participants in the process,

- enlist the young people as co-researchers, that is, to involve, and actively engage the young people in the decision-making process relating to each stage as the research progressed (including the formulation of key research questions, appropriate methods to use to collect data, actual data collection, data analysis, and dissemination).

Thirdly, by engaging young people in the process of the research, the project aimed to contribute to improvements in their mental health and wellbeing through increasing self efficacy and consequent self-esteem. 


\section{Ethics}

Although there are now many examples of participative research projects (Butler, 2003; Hodge, 2005; Braye \& Preston-Shoot, 2005), many tend to overlook complex practicalities and side-step emotional connections or shifting aspirations and understandings (Trevillion, 2004). However, a few studies involving young people have addressed these issues. Smith et al (2002) and McLaughlin (2005) carefully consider the complexities and nuances of a range of issues including exploitation, trust, respect, commitment and enthusiasm. The researchers were mindful of these important elements from the start of the project and attempted to address them in the project design and in the application for ethical approval. McLaughlin also comments on degrees of participation (2007) and, like us, finds there are varying levels of 'involvement' and different interpretations of what constitutes participation.

Ethical approval was sought from the School of Social Sciences and Law at the University of Teesside. Potential risks were to be minimised by providing young researchers with ongoing training, help and support and by assuring and reassuring all participants (young researchers and those researched) about the voluntary nature of involvement and ease of withdrawal at any stage in the research process, and about confidentiality and anonymity (choosing whether their name or identity is included or disguised). In order to adhere to principles of empowerment and respect, young researchers would all be over 17 years of age and parental involvement and consent would not be pursued. Ethical clearance was received.

The research project was designed to involve the young people as designers and practitioners of the research, as co-researchers within the project and not initially as participants. With help and support from the primary researcher, they received appropriate research training over a period of six weeks that enabled them to

- identify potential participants 
- $\quad$ select relevant methods for data collection (e.g. MSN and SMS messaging)

- design and produce interview schedules

- use these methods to collect data

- contribute to writing the reports and the dissemination of the findings

The expectation that involvement in the research process might contribute to some improvements in the young people's health or sense of well-being is an approach which raises the ethical propriety of researching as a form of intervention - an ongoing dilemma for health professionals. However, this is one which is becoming more widely endorsed in mental health research (Tew, et al, 2006) and beginning to be addressed in the context of the service-user involvement agenda (Glasby, 2007).

\section{Methodology}

The authors adopted separate roles in the research process: Carol (with expertise in research ethics) provided consultation and project oversight, Joy (with professional practice experience with young people) worked as the primary researcher with the key support agency and the young researchers. Initially it was agreed that the key support agency (which was also the commissioner of the research), with co-operation from partner agencies, would identify any young people who might be interested in being young researchers, and their names and contact details be provided. It was intended that these young people should be part of the project from the beginning, if interested and willing, to make decisions about research methods and processes, as well as its focus and content. It was also agreed that, whilst this information was being gathered, exploratory and explanatory informal conversations with agency workers and young people would be undertaken and recorded by the primary researcher and that this would become part of the study data. 
The names (and addresses and telephone numbers) of six young people were provided and arrangements were made for them to meet the primary researcher. They included three young women and three young men, all white and aged between 17 and 21 years.

Meeting the young people was relatively straightforward. Securing and maintaining their involvement was less easy. In order to ensure that the young researchers remained central to the project an empowerment model (Tones, 1994) was used. This model ensures that key stakeholders (in this scenario the young researchers) possess a relatively high degree of power. Furthermore, individual empowerment aims to promote and develop key psychological characteristics that include personal control, self-esteem and a realistic self-concept. To this end, the primary researcher offered written and verbal information about herself at the introductory meetings, demonstrating her willingness to share personal as well as professional information and respecting young people's curiosity and scrutiny as valid. The primary researcher also allowed the young people to define and establish group customs in this respect, matching their minimal inquisitiveness by asking them only about their town and local neighbourhoods (and not about themselves or their circumstances). The young people were made aware of the drawbacks as well as benefits from involvement in the research project and, in order to emphasise the areas of influence and elements of control they could maintain, the primary researcher outlined four key points:

- Their involvement in the project as a researcher was voluntary

- The duration, intensity and level of their involvement was entirely up to them

- Each element of their involvement would be paid for (in $£ 5$ vouchers of their choosing)

- None of their decisions (about involvement or withdrawal) needed any justification, explanation or excuse

These were adhered to and reiterated throughout the project. 
Communication between the primary researcher and the young researchers was mostly face-toface in meetings and research sessions, though letters, texts and telephones were also used. The young people engaged in the preliminary stages of the research project with differing levels of intensity. All three young men joined in research sessions, contributed different ideas and expressed various interests. None of the young women engaged with the research project beyond introductory meetings. The young women gave clear reasons for non-involvement including embarrassment (about their involvement with the commissioning agency), reluctance to 'bump into' non-desirable people and the initial acquiescence (to maintain workers' approval) was no longer felt necessary. It is not clear why the young men agreed to be involved (though 'nothing better to do' was alluded to on a number of occasions), nor was there any explanation for only six (out of potentially 100) young people's names being put forward.

Digital cameras were provided as it was intended that these might not only facilitate the young men's engagement, but also assist in the collection of data. Perhaps inspired by the cameras provided at the first planning meetings, the young men revealed many innovative ideas, suggestions and plans about research methods and vehicles, including using text messaging and MSN messenger. Each of the young men favoured a different approach. Again, in order to uphold an empowerment perspective, the researcher adopted four response strategies:

- Recognition and endorsement of ideas and suggestions

- Acknowledgement of their expertise as young, local people in contrast to the primary researcher's lack of expertise as an older, non-local person

- Enthusiasm and encouragement

- Their ongoing agreement to Joy's recording (and potentially using) the discussions in dissemination

The planning meetings also provided opportunities to hear (and begin to accommodate) the young men's varying interests, diary commitments and practical preferences. 
Despite the adoption of an action-empowerment approach to engaging young people as researchers, the young men did not collect any data from any other young person. The authors' aspirations about using cameras, computers and mobile phones were not met. Detailed discussions took place about texting, managing mobile phone credits, choosing between providers, storing and e-mailing messages and sharing SIM cards. Yet no texts were available for use in the research. There were similar discussions about computers and MSN chatrooms, and about technicalities and practicalities of conducting interviews on film, but again, no results were made available. There was also some discussion and considerable effort invested in a questionnaire and interview schedule, which was produced, but no results were forthcoming, either via SMS texting, MSN messages or face-to-face interviews. Furthermore, the digital video and still cameras were borrowed and used, but the young researchers did not produce any tangible results in this way. Questions as to why the young researchers did not produce any tangible results were not asked because this would have been diametrically opposed to the empowerment model adopted, remembering statements made to the young researchers at the outset of the project assuring them that their involvement or withdrawal did not require justification, explanation or excuse.

Because of this, the data that was generated (and comprise the findings in this paper) were derived from conversations with and between the young researchers, as well as from conversations with staff at the commissioning agency and in partner agencies. The detailed preparations for and discussions around using the equipment raised a number of interesting issues, and again, these conversations became the data for the study rather than the intended and expected rich descriptions derived from and by the young researchers. 


\section{Data Analysis}

The lack of tangible results from the young researchers meant that the research notes collected from the exploratory and explanatory informal conversations 'became' the data. These notes were made by the primary researcher during and after the meetings and training sessions between herself and the three young researchers, and also during and after discussions with members of staff at the commissioning and partner agencies. These data were transcribed by the primary researcher and then analysed using thematic content analysis by both authors independently of each other. By this stage of the project, two more young people had withdrawn and only one young man was willing to continue his involvement. Burnard's (1991) 14 stages of analysis were followed to aid the description and interpretation of the data. In thematic content analysis the transcriptions are categorized using themes or codes, that is chunks of text are taken and labelled under certain categories, which enables later retrieval and analysis (Joffe \& Yardley, 2004). The aim of analysis was to produce a detailed and systematic recording of the themes and issues that emerged from the interviews. The one remaining young researcher shared his views and reflections on progress throughout this period of analysis.

Following Burnard's (1991) recommendations analysis began with notes that were made, which detailed initial ideas and thoughts relating to the discussions. Once the discussions and notes were transcribed they were read through and initial codes were noted on the transcriptions. The transcriptions were then read again which Burnard (1991) suggests leads to 'immersion' in the data. Notes were then made more specifically regarding themes that emerged from the transcriptions on both the manifest and latent content of the transcriptions. The transcripts were then coded into themes and sub-themes and sections were collated under headings and subheadings into a coding frame. The coding frame introduced a systematic element to analysis and facilitated analysis of the combination of frequency of codes with their meaning in context, to add depth to analysis (Joffe \& Yardley, 2004). Each theme was exclusive, with text only attributable 
to one theme. Following this first stage of analysis, both the authors then compared the themes they had extracted, and commonalities between these themes were discussed. Once agreement had been reached in relation to the emergent themes further consideration was given to the data by the remaining young researcher. Specifically, this led to comparisons between individual comments and discussion of any commonalities or differences among the young researchers. The emergent themes were People, Places and Money.

\section{Discussion of Results}

The young researchers talked knowledgeably about money. They appeared to know about different benefits and grants and about different rates of supplements and deductions. They could demonstrate a sophisticated appreciation of the pros and cons of working for different companies and possessed a repertoire of opinions about benefit payments and claiming methods. They also seemed to keep abreast of up-to-date detailed information, for example as to minimum wage rates for $18-21$ year olds (which they thought were unjust). On the whole, Government schemes were felt to be particularly exploitative, especially some of the 'modern apprenticeships' which paid minimum rates.

A great deal of the young researchers' conversations with each other was about whom they knew, whether the others also knew them and what was thought about them. These exchanges revealed a number of facts about networks and knowledge and also raised important issues. The young researchers, although not living in the same areas, knew (or knew of) each other and seemed to know (or know of) many of each other's friends and acquaintances. Their discussions focussed on whom they knew and how they 'rated' them in terms of being 'alright' or 'not alright', but did not discuss personal details and did not consider the quality of relationships or connections. Occasionally they would relate stories about individual's exploits or describe incidents they had seen or being part of. On the whole, the people they talked about were a lot like themselves, young men from the town, but they also spoke about those who were deemed to 
be unlike themselves. One of these 'groups' were known as 'muck tans', referring to people who were dirty and, by association, poor. It was not clear whether this term had any ethnic or racist connotations, but on the whole these people were to be shunned and laughed at.

The easy identification of other people as inferior or subordinate could be described as 'identityprotecting' behaviour (Brown, 2000). According to Brown, such maintenance strategies are particularly relevant to 'low-status' groups who use a variety of ways of reinterpreting significant social signs and identifications, and collectively asserting superiority. The young researchers also identified individuals and groups of young people whom they classified as 'troublesome ones', who generally were not included in projects or schemes. These young people may visit agencies or be put forward for events or appointments, but usually didn't attend. Much of their behaviour was referred to as 'chewing on' (messing about and annoying) and occasionally this was associated with alcohol. All three young researchers talked about drinking alcohol, about gangs of youths on the streets scaring old people, and admitted that they scared them too (especially if in a big crowd). However, they were able to distance themselves from these behaviours to some extent, 'we're not young and daft now, it's kids want to drink'. The young researchers therefore demonstrated a number of maintenance strategies to establish identity and preserve self-esteem. They confirmed they were less dirty and less poor than others, they were also less troublesome and more mature.

The young researchers also talked about places where they might go to drink, but did not discuss any other leisure activities or venues. The researcher asked about other places, for example sports centres, but the young researchers said young people they knew did not use them. All three young researchers talked about places they had worked and where their friends had worked. They discussed various retail outlets, factories and call centres and considered the merits (or otherwise) of different shift patterns and working arrangements. One of the young 
researchers worked on a voluntary basis in an Internet café and talked about its friendly and easy atmosphere. This was in contrast to some of the other work places that were discussed. Bullying occurred on training schemes as well as at school, and boredom was another feature of their experiences. Two of the young researchers had worked at a local call centre and one of them had found that boredom was a major feature in his reason for leaving after only three weeks. The other, who worked there longer, didn't like his colleagues. He found the supervisors were quite sarcastic and cruel and many of the men were gay - which he didn't like. This young researcher said he left because of the low pay.

Overall, although the three themes were not what the authors' had expected, they closely link to issues around mental health and wellbeing. They seemed to indicate that young people were greatly skilled at the business of surviving in their NEET (not in education, employment or training) world. By adjusting and re-calculating financial information, balancing expectations with limited realities, focussing on short-term and day-to-day plans, appraising possibilities, networking and knowing communities and key individuals and avoiding difficult or dangerous situations, they managed to assert their identities and maintain self-esteem. By embracing the NEET identity, they were protecting themselves from disappointment and defending their self-esteem. Without aspiring too far, and by keeping some connection to services and agencies, however peripherally, they could also maintain their knowledge base, remain reasonably secure and stay mentally well.

Whilst the findings provide insight into the world of the young person who is NEET, the research aims of the project were only partly met. That is, we were able to gain a greater understanding of the needs and achievements of young people categorised as NEET but were unable to identify areas for future support service development that was directly derived from the young people themselves. We were able to actively engage young people in the research project as coresearchers and involve them in the decision-making process relating to each stage of the project 
even though they did not meet our expectations in relation to the espoused data collection methods. In so doing our aim of empowerment of the young people was met, whereas observed improvements in metal health were only seen for the one young man who stayed longest in the project.

\section{Discussion of research process}

Analysis of the methodological process is less conclusive. The absence of research 'data', in the traditional sense, was a major feature of this research project and most probably links to our ambivalence (as social work and health professionals and researchers) about relationships with young people. On the one hand we are encouraged by government policies, and often by the moral high ground, to regard young people as social actors who are to be consulted, included and empowered wherever possible; we are even more earnestly encouraged when the young people are excluded and marginalized in society. On the other hand, through our own practice experience and knowledge of the research evidence, we are all too aware of the quite understandable suspicion and reluctance of such young people to engage with us, and the subsequent difficulties of sustaining that engagement. We wanted to include and empower them but also wanted to acknowledge and respect their reluctance and recalcitrance. We therefore continue to question the practical and ethical implications of recruiting such young people to actively participate in research and other decision-making endeavours. As such, whilst the methodological approach taken in this study seems to fit with the wider literature (see Smith et al 2002), it would appear that with particularly hard-to-reach groups of young people (i.e. for those who are by definition NEET) the costs and benefits of engaging collaboratively in the research process may undermine the intended aims of the proposed research (McLaughlin, 2006). However, we have attempted to report on the actual data and outcomes of the study rather than focus on the intrinsic benefits of participation to our co-researchers (see Carr, 2004) as an 
attempt to move away from merely reporting on the research process. To this end, the methodological approach adopted served its purpose, insofar as the young co-researchers were 'empowered' or, at least were not 'dis-empowered', from following their own agenda.

On a practical level, the young people made their own decisions; they decided (on the whole) not to participate, and those that did participate decided not to use the equipment or methods provided. It is unlikely however, that these decisions were made from a basis of power - as they had no part in the initial commissioning decisions about direction, appointment or funding of the research project.

The ethical implications similarly relate to issues of power. Although our aims had been to employ an 'action-empowerment' approach in order that we might actively engage and empower young people, this was not achieved. Young women were not engaged. The young men who were, were already empowered by their social position, personal and group identity and it is doubtful whether involvement in the research project had any part in empowering them further. Indeed, it sometimes felt exploitative rather than empowering. In contrast, we (like other researchers and authors) continue to reap benefits; this and other publications contribute to our employment and professional prospects and enhance our academic reputations (Dominelli, 2005).

\section{Conclusion}

In recent years, health and social care research has engaged with issues of exclusion and empowerment, (e.g. see Hodge, 2005; Ramon, 2003) alongside a growing interest in research with hard-to-reach groups and particularly with young people (Dominelli, 2005; McLaughlin, 2005). This research project builds upon this work, focusing upon young people who are NEET and illustrates how ambivalence and power impact upon the research process and outputs. 
Although results were limited, the relevance of these to the young people's lives became evident. Particularly, the marked observed increase in social engagement and improved wellbeing for one of the young men, evidenced by changes to his demeanour and through his apparent increasing confidence in social situations. Indeed, some months after the completion of the project, this young man secured permanent employment and played a major part in dissemination of the research (Trotter \& Longwill, 2005). As such, professionals may wish to continue to work and research in this way because of the 'bi-product' of improvements to mental health and wellbeing for this at-risk group. As a research methodology, participative and action-empowerment approaches are not 'gold standard' but as a practice approach they have four key benefits and need to be developed further. That is, that they can be done with both individuals and groups; they generate person-specific information; they are service-user / expert-patient focussed (and therefore match current UK policy trends); and they can improve people's health and may make them feel better.

Collectively therefore, although these four key benefits may not go far in terms of empowerment, they may well reduce professionals' and service-users' disappointments about service provision by improving decision making and strengthening participative relationships. They may also encourage research designers and commissioners to extend their ideas and aspirations. As we found in this project, despite ethical and practical hurdles and doubts, it is possible to explore less tangible subjects and to work with 'invisible', harder-to-reach populations. In a small measure, our disappointments were temporary and disempowerments transitory. Furthermore, the unplanned and unexpected directions that the research took proved, for one of the young men at least, to be empowering and beneficial. 


\section{References}

Aggleton, P., Hurry, J. \& Warwick, I. (Eds.) (2000) Young People and Mental Health, Wiley, Chichester.

Anderson, C. (2005) 'On the edge', Community Care, 24.03.05, pp. 36-37.

Baker, S. R. (2003) 'A prospective longitudinal investigation of social problem-solving appraisals on adjustment to university, stress, health, and academic motivation and performance', Personality and Individual Differences, Vol. 35, no. 3, pp. 569-591.

Bennett, A. Cieslik, M. \& Miles, S. (eds.) (2003) Researching Youth. Basingstoke:

Palgrave/Macmillan.

Braye, S. \& Preston-Shoot, M. (2005) 'Emerging from out of the shadows? Service-user and carer involvement in systematic reviews', Evidence \& Policy, Vol. 1, no. 2, pp. 173-194.

Brown, R. (2000) 'Social identity theory: past achievements, current problems and future challenges', European Journal of Social Psychology, Vol. 30, no. 6, pp. 745-778.

Burnard, P. (1991) 'A method of analyzing interview transcripts in qualitative research', Nurse Education Today, Vol. 11, no. 6, pp. 461-466.

Butler, A. (2003) 'Whose life is it anyway? Creative autobiography with service users', In Users Researching Health and Social Care: An Empowering Agenda? ed. S. Ramon, Venture Press, Birmingham, pp. 35-44.

Carr, S. (2004) Has Service User Participation Made a Difference to Social Care Services? SCIE and Policy Press, London.

Carrick, R., Mitchell, A. \& Lloyd, K. (2001) 'User involvement in research: power and compromise', Journal of Community \& Applied Social Psychology, Vol. 11, no. 3, pp. 217225.

Clough, R., Green, B., Hawkes, B., Raymond, G. \& Bright, L. (2006) Older People as Researchers: Evaluating a Participative Project, Joseph Rowntree Foundation, York. 
Crowley, P., Kilroe, J. \& Burke, S. (2004) Youth Suicide Prevention: Evidence Briefing, National Health Service, Health Development Agency, London.

Department of Health (2004) From Here To Equality: A Strategic Plan to Tackle Stigma and Discrimination on Mental Health Grounds 2004-2009, National Institute for Mental Health in England, Leeds.

Dominelli, L. (2005) 'Social inclusion in research: reflecting on a research project involving young mothers in care', International Journal of Social Work, Vol. 14, no. 1, pp. 13-22.

Evans, K. Rudd, P. Behrens, M. Kaluza, J. \& Woolley, C. (2003) Taking Control: Young Adults Talking about the Future in Education, Training and Work, The National Youth Agency, Leicester:

Faulkner, A. \& Thomas, P. (2002) 'User-led research and evidence-based medicine', British Journal of Psychiatry, Vol. 180, no. 1, pp. 1 -3.

Ferns, P. (2005) 'Finding a way forward: a Black perspective on social approaches to mental health', in Social Perspectives on Mental Health: Developing Social Models to Understand and Work with Mental Distress, ed. J. Tew, Jessica Kingsley, London.Fortune, S., Stewart, S., Yadav, V., \& Hawton K. (2007) 'Suicide in adolescents: using life charts to understand the suicidal process', Journal of Affective Disorders, Vol. 100, nos. 1-3, pp. 199-210.

Gilchrist, H. \& Sullivan, G. (2006) ‘Barriers to help-seeking in young people: community beliefs about youth suicide', Australian Social Work, Vol. 59, no. 1, pp. 73-85.

Glasby, J. (2007) 'In whose interests? Local research ethics committees and service user research', Ethics and Social Welfare, Vol. 1, no. 3, pp. 282-292.

Hanley, B., Bradburn, J., Barnes, M., Evans, C., Goodare, H., Kelson, M., Kent, A., Oliver, S., Thomas, S. \& Wallcraft, J. (2004) Involving the Public in NHS, Public Health and Social Care: Briefing Notes for Researchers, Involve, Eastleigh.

HM Treasury \& Department for Education \& Skills (2007) Policy Review of Children and Young People: A Discussion Paper, HMSO, London. 
Hodge, S. (2005) 'Participation, discourse and power: a case study in service user involvement', Critical Social Policy, Vol. 25, no. 2, pp. 164-179.

Joffe, H. \& Yardley, L. (2004) 'Content and thematic analysis', in Research Methods for Health and Clinical Psychologists, eds. D. F. Marks \& L. Yardley, Sage, London.

Jones, M., Salmon, D. \& Orme, J. (2004) 'Young people's involvement in a substance misuse communications campaign', Drugs: Education, Prevention \& Policy, Vol. 11, no. 5, pp. $391-405$.

Keen, A. W. (1994) 'Using music as a therapy tool to motivate troubled adolescents', Social Work in Health Care Vol. 39, no. 3-4, pp. 361-373.

Leamy, M. \& Clough, R. (2002) 'Older people as researchers: their role in a research project', Education and Ageing, Vol. 16, no. 3, pp. 279-87.

Lowes L. \& Hulatt, I. (eds.) (2005) Service Users' Involvement in Health and Social Care Research, Routledge, London.

Marks, D. F. \& Yardley, L. (eds.) (2004) Research Methods for Health and Clinical Psychologists, Sage, London.

McLaughlin, H. (2005) 'Involving young service users as co-researchers: possibilities, benefits and costs', British Journal of Social Work, Vol. 36, no. 8, pp. 1395-1410.

McLaughlin, H. (2006) Understanding Social Work Research, Sage, London.

McLaughlin, H. (2007) 'Ethical issues in the involvement of young service users in research', Ethics and Social Welfare, Vol. 1, no. 2, pp. 176-193.

McLeod, A. (2008) 'Whose agenda? Issues of power and relationship when listening to lookedafter young people', Child \& Family Social Work, Vol. 2, no. 3, pp. 278-286.

Morrison, L. L. \& L’Heureux, J. (2002) ‘Suicide and gay/lesbian/bisexual youth: implications for clinicians', Journal of Adolescence, Vol. 24, no. 1, pp. 39-49. 
National Institute for Mental Health in England (2006) Reaching Out: Evaluation of Three Mental Health Promotion Pilots to Reduce Suicide among Young Men, National Institute for Mental Health in England, Leeds.

Oliver, C. \& Storey, P. (2006) Evaluation of Mental Health Pilots to Reduce Suicide Amongst Young Men: Final Report, Thomas Coram Research Unit, London.

Ramon, S. (ed.) (2003) Users Researching Health and Social Care: An Empowering Agenda? Venture Press, Birmingham.

Ross, F., Donovan, S., Brearley, S., Victor, C., Cottee, M., Crowther, P. \& Clark, E. (2005) 'Involving older people in research: methodological issues', Health \& Social Care in the Community, Vol. 13, no. 3, pp. 268-275.

Smalley, N., Scourfield, J. \& Greenland, K. (2005) 'Young people, gender and suicide: a review of research on the social context', Journal of Social Work, Vol. 5, no. 2, pp. 133-154.

Smith, R., Monaghan, M. \& Broad, B. (2002) 'Involving young people as co-researchers: facing up to the methodological issues', Qualitative Social Work, Vol. 1, no. 2, pp. 191-207.

Stanley, N. (2005) Parents' perspectives on young suicide, Children and Society, Vol. 19, no. 4, pp. 304-315.

Swann, S. K. \& Spivey, C. A. (2004) 'The relationship between self-esteem and lesbian identity during adolescence', Child and Adolescent Social Work Journal, Vol. 21, no. 6, pp. 629648.

Tew, J., Gould, N., Abankwa, D., Barnes, H., Beresford, P., Carr, S., Copperman, J., Ramon, S., Rose, D., Sweeney, A. \& Woodward, L. (2006) Values and Methodologies for Social Research in Mental Health, Social Perspectives Network, London.

Thornton, H. (2002) 'Patient perspectives on involvement in cancer research in the UK', European Journal of Cancer Care, Vol. 11, no. 3, pp. 205 -209. 
Tones, K (1994) 'Health promotion, empowerment and action competence', in Action and Action Competence as Key Components in Critical Pedagogy, eds. B. Jensen and K. Schnack, Royal Danish School of Educational Studies, Denmark.

Trevillion, S. (2004) 'Social work research and the partnership agenda', in Reflecting on Social Work - Discipline and Profession, eds. R. Lovelock, K. Lyons \& J. Powell, Ashgate, Aldershot.

Trickey, D. (2005) 'Young people bereaved by suicide', Bereavement Care, Vol. 24, no. 1, pp. 1114.

Trivedi, P. \& Wykes, T. (2002) 'From passive subjects to equal partners: qualitative review of user involvement in research', British Journal of Psychiatry, Vol. 181, no. 6, pp. $468-472$.

Trotter, J. \& Longwill, L. (2005) 'Who’s involved? Evaluation, assessment and research about young people', Evaluation for Practice conference, Huddersfield University, [July 13-15 2005].

Turner, S. G., Kaplan, C. P. \& Badger, L. W. (2006) 'Adolescent Latinas' adaptive functioning and sense of well-being', Affilia, Vol. 21, no. 3, pp. 272-281.

University of Sheffield, School of Health \& Related Research (ScHARR) (2005) SCIE Research Briefing 17: Therapies and Approaches for Helping Children and Adolescents who Deliberately Self-Harm (DSH), Social Care Institute for Excellence, London. 